Article

\title{
Predicting the Thermodynamic Ideal Glass Transition Temperature in Glass-Forming Liquids
}

\author{
Qian Gao@ and Zengyun Jian * \\ School of Materials and Chemical Engineering, Xi'an Technological University, Xi'an 710021, China; \\ xian1504@126.com \\ * Correspondence: jianzengyun@xatu.edu.cn
}

Received: 7 April 2020; Accepted: 1 May 2020; Published: 6 May 2020

check for updates

\begin{abstract}
The Kauzmann temperature $T_{\mathrm{K}}$ is a lower limit of glass transition temperature, and is known as the ideal thermodynamic glass transition temperature. A supercooled liquid will condense into glass before $T_{\mathrm{K}}$. Studying the ideal glass transition temperature is beneficial to understanding the essence of glass transition in glass-forming liquids. The Kauzmann temperature $T_{\mathrm{K}}$ values are predicted in 38 kinds of glass-forming liquids. In order to acquire the accurate predicted $T_{\mathrm{K}}$ by using a new deduced equation, we obtained the best fitting parameters of the deduced equation with the high coefficient of determination $\left(R^{2}=0.966\right)$. In addition, the coefficients of two reported relations are replaced by the best fitting parameters to obtain the accurate predicted $T_{\mathrm{K}}$, which makes the $R^{2}$ values increase from 0.685 and 0.861 to 0.970 and 0.969 , respectively. Three relations with the best fitting parameters are applied to obtain the accurate predicted $T_{\mathrm{K}}$ values.
\end{abstract}

Keywords: glass transition temperature; fragility parameter; Kauzmann temperature; thermodynamic ideal glass transition temperature; glass-forming liquid

\section{Introduction}

If crystallization can be avoided by sufficiently rapid cooling, a supercooled liquid will become a glassy state at glass transition temperature $T_{\mathrm{g}}$, at which the viscosity of the supercooled liquid is typically $10^{12} \mathrm{~Pa} \mathrm{~s}$ (10 poise $=1 \mathrm{~Pa} \mathrm{~s}$ ) [1-5]. Liquid-glass transitions are generally observed in various supercooled liquids, including molecular liquids, ionic liquids, metallic liquids, oxides, and chalcogenides $[5,6]$. Figure 1 shows the temperature dependence of the entropy difference between various supercooled liquids and their crystalline phases [5,7]. With temperature decreases, their entropic surplus is consumed, and the glass transition sets in when the slope of the curve changes. For lactic acid, its glass transition temperature $T_{\mathrm{g}}$ has been marked in Figure 1. Its curve can then be extrapolated to the Kauzmann temperature $T_{\mathrm{K}}$, at which point $\Delta S$ will vanish. In other words, the entropy of the supercooled liquid equals the entropy of its crystalline counterpart at $T_{\mathrm{K}}$. Below $T_{\mathrm{K}}$, the entropy of the supercooled liquid will become less than that of its crystalline phase. However, it is difficult to see how a disordered and nonperiodic liquid has a lower entropy than a periodic crystal of the same density [8]. As a consequence, Kauzmann temperature $T_{\mathrm{K}}$ is a lower limit of glass transition temperature (i.e., the thermodynamic ideal glass transition temperature) and the supercooled liquid will condense into glass, having the same entropy as the perfect crystal at $T_{\mathrm{K}}[8]$.

The glass transition temperature $T_{\mathrm{g}}$ plays an important role in liquid-glass transition. $T_{\mathrm{g}}$ has significant thermophysical properties for predicting glass-forming ability (GFA) and the stability of glass formers. Thermodynamically, the lowest value of $T_{\mathrm{g}}$ is the Kauzmann temperature $T_{\mathrm{K}}$ for a certain glass-forming liquid. In other words, the Kauzmann temperature $T_{\mathrm{K}}$ is the lowest temperature at which a supercooled liquid can exist. The Kauzmann temperature $T_{\mathrm{K}}$ is studied, which is beneficial to understand the nature of glass transition, and to find a correlation between the measured glass 
transition temperature $T_{\mathrm{g}}$ and the thermodynamically ideal glass transition temperature $T_{\mathrm{K}}$. In addition, it can be seen that fragility parameter $m$ is related to $T_{\mathrm{g}}$ and $T_{\mathrm{K}}$ (see below). The fragility parameter $m$ is applied to describe the degree of departure from an Arrhenius relation of the temperature dependence of viscosity. That is, $T_{\mathrm{g}}$ and $T_{\mathrm{K}}$ can also be applied to describe the temperature dependence of viscosity in glass-forming liquids. Therefore, studying the temperature $T_{\mathrm{K}}$ is a classic problem in amorphous materials. $T_{\mathrm{K}}$ temperatures in various glass-forming liquids have been calculated, such as in metallic liquids [4,9-16], molecular liquids [6,17], ionic liquids [6,17], and oxides [6,12]. The Kauzmann temperature $T_{\mathrm{K}}$ will be predicted by $T_{\mathrm{g}}$ and $m$ in glass-forming liquids.

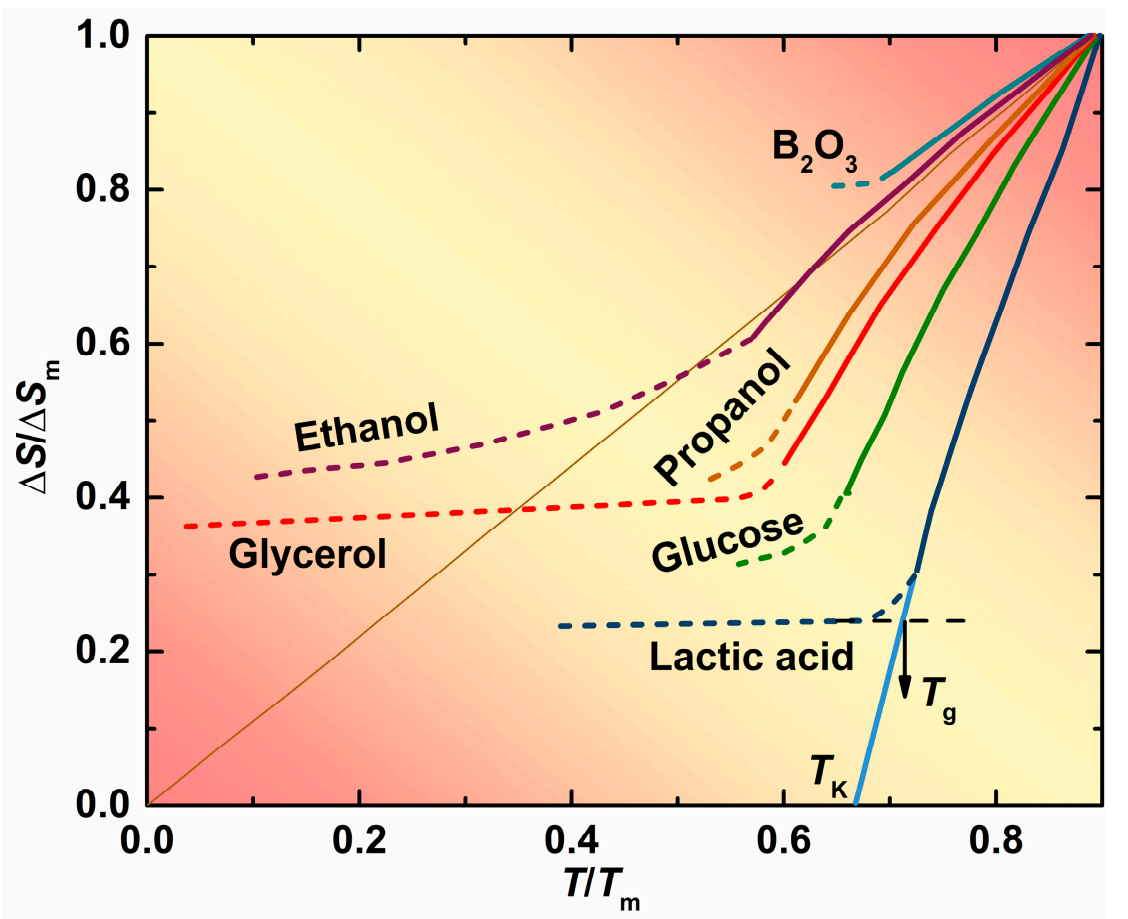

Figure 1. Temperature dependence of the difference in entropy between various supercooled liquids and their crystalline phases. $\Delta S_{\mathrm{m}}$ and $T_{\mathrm{m}}$ are the melt entropy and the melting temperature, respectively. (Adapted from Ref. [5,7]).

\section{Expressions of Predicting $T_{K}$}

Universally, $T_{\mathrm{K}}$ can be acquired by $[5,9,11,14,18]$ :

$$
\Delta S_{m}=\int_{T_{K}}^{T_{m}} \frac{\Delta c_{p}^{l-c}(T)}{T} d T
$$

where $\Delta S_{\mathrm{m}}$ is the entropy of fusion at the melting point $T_{\mathrm{m}}$, and $\Delta c_{\mathrm{p}}{ }^{1-\mathrm{c}}(T)$ is the specific heat capacity difference between the supercooled liquid and its crystalline counterpart. If $\Delta S_{\mathrm{m}}$ and $\Delta c_{\mathrm{p}}{ }^{1-\mathrm{c}}(T)$ are acquired, $T_{\mathrm{K}}$ will be calculated. The entropy of fusion $\Delta S_{\mathrm{m}}$, can be obtained by $\Delta S_{\mathrm{m}}=\Delta H_{\mathrm{m}} / T_{\mathrm{m}}$, where $\Delta H_{\mathrm{m}}$ is the heat of fusion, which can be obtained by the integration of the melting peak [19]. The so-called "step method", which consists of heating the sample to a certain temperature with a constant rate, and then annealing isothermally during each step, can be applied to determine the specific heat capacity of the sample on heating, in reference to the specific heat capacity of a standard sapphire $[4,15]$. The data of $c_{\mathrm{p}}(T)_{\text {sample }}$ can be calculated by the following equations $[4,15]$ :

$$
c_{p}(T)_{\text {sample }}=\frac{Q_{\text {sample }}^{*}-Q_{\text {pan }}^{*}}{Q_{\text {sapphire }}^{*}-Q_{\text {pan }}^{*}} \times \frac{m_{\text {sapphire }} \times \mu_{\text {sample }}}{m_{\text {sample }} \times \mu_{\text {sapphire }}} \times c_{p}(T)_{\text {sapphire }}
$$


where $c_{\mathrm{p}}(T)_{\text {sample }}$ and $c_{\mathrm{p}}(T)_{\text {sapphire }}$ are the specific heat capacity of sample and sapphire, respectively, $m_{i}$ the mass, $\mu_{i}$ the mole mass, and $Q_{i}^{*}$ the heat flux. Meanwhile, the temperature dependence of the specific heat capacity $c_{\mathrm{p}}^{\text {liquid }}(T)$ of the supercooled liquid can be expressed as $[4,11,15]$ :

$$
c_{p}(T)=3 R+a \cdot T+b \cdot T^{-2}
$$

where $R$ is gas constant. The specific heat capacity $c_{\mathrm{p}}{ }^{\text {crystal }}(T)$ of the crystal can be expressed as $[4,11,15]$ :

$$
c_{p}(T)=3 R+c \cdot T+d \cdot T^{2}
$$

The parameters of expressions for $c_{\mathrm{p}}{ }^{\text {liquid }}(T)$ and $c_{\mathrm{p}}{ }^{\text {crystal }}(T)$ can be determined by fitting the data measured in steps in reference to sapphire. Therefore, the specific heat capacity difference between the supercooled liquid and its crystalline counterpart can be calculated by Equations (3) and (4), with the known parameters. $T_{\mathrm{K}}$ can be calculated by the above formulas so far. From the above analysis, acquiring the Kauzmann temperature $T_{\mathrm{K}}$ is cumbersome and time-consuming. Therefore, the easily obtained parameters are applied to predict $T_{\mathrm{K}}$.

The Angell's fragility parameter $m$, based on viscosity or relaxation time, is defined as [1,20-23]:

$$
m=\left.\frac{d \lg (\eta)}{d\left(T_{g} / T\right)}\right|_{T=T_{g}}=\left.\frac{d \lg (\tau)}{d\left(T_{g} / T\right)}\right|_{T=T_{g}}=\frac{D T_{0} T_{g}}{\left(T_{g}-T_{0}\right)^{2} \ln (10)}
$$

A similar fragility has been defined as [17]:

$$
m_{S}=\left.\frac{d\left[\frac{\lg (\eta(T)) / \eta_{0}}{\lg \left(\eta\left(T_{g}\right) / \eta_{0}\right)}\right]}{d\left(T_{g} / T\right)}\right|_{T=T_{g}}=\frac{m}{m_{\min }}
$$

where $m_{\min }=\log _{10}\left(\eta_{\mathrm{g}} / \eta_{0}\right) . \eta_{\mathrm{g}}$ denotes viscosity (typically $10^{12} \mathrm{~Pa} \mathrm{~s}$ ) at glass transition temperature $T_{\mathrm{g}}$. $\eta_{0}$ is the high temperature limit of viscosity, which can be determined by the following equation [2,24]:

$$
\eta_{0}=h N_{\mathrm{A}} \rho / M
$$

where $h$ is Planck's constant, $N_{\mathrm{A}}$ is Avogadro's number, $\rho$ is the density of the liquid and $M$ is the molar mass. The $\eta_{0}$ value is about set as $10^{-5} \mathrm{~Pa} \mathrm{~s}[2,17,24-26]$. Thus, generally, the $\log _{10}\left(\eta_{\mathrm{g}} / \eta_{0}\right)$ value is equal to 17 . The expressions related to $T_{\mathrm{K}}$ have been studied, and they can be utilized to calculate $T_{\mathrm{K}}$, which make calculation simpler. $T_{\mathrm{K}}$ as a function of $T_{\mathrm{g}}$ and Angell's fragility parameter $m$ has been reported, and the expression can be described by $[1,16,17,25]$ :

$$
m_{s}=\frac{m}{m_{\min }}=\frac{T_{g}}{T_{g}-T_{K}}
$$

From Equation (8), $T_{\mathrm{K}}$ can be expressed as:

$$
T_{K}=T_{g}-m_{\min } T_{g} / m
$$

The other expression of $T_{\mathrm{K}}$ as a function of $T_{\mathrm{g}}$ and $m$ can be expressed as $[1,16,17,25]$ :

$$
m_{s}=\frac{m}{m_{\min }}=\frac{T_{g}^{2}+T_{K}^{2}}{T_{g}^{2}-T_{K}^{2}}
$$

Equation (10) is transformed into:

$$
T_{K}=T_{g} \times\left[\left(m-m_{\min }\right) /\left(m+m_{\min }\right)\right]^{1 / 2}
$$


Furthermore, a new expression of predicting $T_{\mathrm{K}}$ as a function of $T_{\mathrm{g}}$ and $m$ is also deduced by us, and this expression is derived as follows. Another expression of the Kauzmann temperature is presented by [27]:

$$
T_{K}=T_{m}\left(1+\frac{\Delta H_{m}}{T_{g} \Delta c_{p}^{l-c}\left(T_{g}\right)}\right)^{-1}
$$

Additionally, $m$ can be calculated by the following Equation [27]:

$$
m=\Lambda_{a} \frac{\Delta c_{p}^{l-g}\left(T_{g}\right)}{\Delta S_{m}}
$$

where $\Lambda_{\mathrm{a}}$ is the constant and equals $40 . \Delta c_{\mathrm{p}}{ }^{1-\mathrm{g}}\left(T_{\mathrm{g}}\right)=c_{\mathrm{p}}{ }^{\text {liquid }}\left(T_{\mathrm{g}}\right)-c_{\mathrm{p}}{ }^{\text {glass }}\left(T_{\mathrm{g}}\right)$ is the specific heat capacity difference between the supercooled liquid and its glass state at $T_{\mathrm{g}}$. When $\Delta c_{\mathrm{p}}{ }^{1-\mathrm{g}}\left(T_{\mathrm{g}}\right)$ is replaced by $\Delta c_{\mathrm{p}}{ }^{\mathrm{l}-\mathrm{c}}\left(T_{\mathrm{g}}\right)$, the numerical factor would increase from 40 to 43 , but the quality of the correlation remains unchanged, where $\Delta c_{\mathrm{p}}{ }^{1-\mathrm{c}}\left(T_{\mathrm{g}}\right)=c_{\mathrm{p}}{ }^{\text {liquid }}\left(T_{\mathrm{g}}\right)-c_{\mathrm{p}}{ }^{\text {crystal }}\left(T_{\mathrm{g}}\right)$ is the specific heat capacity difference between the supercooled liquid and its crystalline counterpart at $T_{\mathrm{g}}$ [27]. Hence, $\Delta c_{\mathrm{p}}{ }^{1-\mathrm{g}}\left(T_{\mathrm{g}}\right)$ is replaced by $\Delta c_{\mathrm{p}}{ }^{1-\mathrm{c}}\left(T_{\mathrm{g}}\right)$, and $m$ can be expressed as:

$$
m=\Lambda_{b} \frac{\Delta c_{p}^{l-c}\left(T_{g}\right)}{\Delta S_{m}}
$$

where $\Lambda_{\mathrm{b}}$ is the constant and equals 43 . The ratio $T_{\mathrm{m}} / T_{\mathrm{g}}$ is about constant $\Lambda_{\mathrm{c}}$, which equals $3 / 2$ [27-30]. Plugging this $T_{\mathrm{m}} / T_{\mathrm{g}}$ relation into Equation (14):

$$
m=\Lambda_{b} \Lambda_{c} T_{g} \frac{\Delta c_{p}^{l-c}\left(T_{g}\right)}{\Delta H_{m}}
$$

From Equation (12) and Equation (15), we obtain:

$$
T_{K}=\Lambda_{c} T_{g}\left(1+\frac{\Lambda_{b} \Lambda_{c}}{m}\right)^{-1}=\Lambda_{c} T_{g}\left(\frac{m}{m+\Lambda_{b} \Lambda_{c}}\right)
$$

The expanded Equation (16) can be expressed by:

$$
T_{K}=\Lambda_{c} T_{g}-\Lambda_{b} \Lambda_{c}^{2} \frac{T_{g}}{m+\Lambda_{b} \Lambda_{c}}
$$

It can be seen that these expressions of predicting $T_{\mathrm{K}}$ are expressed as the function of $T_{\mathrm{g}}$ and $m$ from Equations (9), (11), and (17). Because $T_{\mathrm{g}}$ and $m$ have been reported for a lot of glass-forming liquids, predicting $T_{\mathrm{K}}$ will be made simpler and more convenient by the above formulae.

\section{Methods}

As can be seen from the above, Equations (9), (11), and (17) can be applied to predict $T_{\mathrm{K}}$. In order to obtain accurate $T_{\mathrm{K}}$ values, the coefficient of determination, $R^{2}$ is applied to evaluate the accuracy of the predicted $T_{\mathrm{K}}$. In statistics, generally, $R^{2}$ is defined as: $R^{2}=1-\mathrm{SS}_{\mathrm{res}} / \mathrm{SS}_{\mathrm{tot}}$, where $\mathrm{SS}_{\text {res }}$ is the sum of squares of residuals and $\mathrm{SS}_{\text {tot }}$ is the total sum of squares. $R^{2}$ is a statistical measure of how well the predicted $T_{\mathrm{K}}$ values approximate the reported $T_{\mathrm{K}}$ values. The higher is the $R^{2}$ value $\left(0 \leq R^{2} \leq 1\right)$, the more accurate is the predicted $T_{\mathrm{K}}$. The predicted $T_{\mathrm{K}}$ values perfectly fit the reported $T_{\mathrm{K}}$ when $R^{2}$ equals 1.

\section{Results and Discussion}

The values of the glass transition temperature $T_{\mathrm{g}}$, Angell's fragility parameter $m$, and the Kauzmann temperature $T_{\mathrm{K}}$ for various glass formers are listed in Table 1. Figure 2a shows the predicted Kauzmann 
temperature $T_{\mathrm{K}}{ }^{\text {cal1 }}$, according to Equation (9) at $m_{\min }=17$. Many reported $T_{\mathrm{K}}$ values for various glass formers do not fall on the curve of the predicted $T_{\mathrm{K}}$ cal1. Meanwhile, the $R^{2}$ value of this correlation equals 0.685 , which is relatively low. It indicates that the predicted $T_{\mathrm{K}}{ }^{\text {call }}$ values by using Equation (9) at $m_{\min }=17$ are inaccurate. Although the $\log _{10}\left(\eta_{\mathrm{g}} / \eta_{0}\right)$ (i.e., $\left.m_{\min }\right)$ value is generally equal to 17 , the viscosity change in the glass transition is approximately two orders of magnitude [16,18]. Therefore, the $\log _{10}\left(\eta_{\mathrm{g}} / \eta_{0}\right)$ value is considered to have a range from 15 to 17 [16]. In fact, generally, the $\eta_{0}$ value is set as about $10^{-5} \mathrm{~Pa}$ s, but $\eta_{0}$ values have differences in some amorphous materials [31]. This will cause a change of the $\log _{10}\left(\eta_{\mathrm{g}} / \eta_{0}\right)$ value as well. In our previous study, the $\log _{10}\left(\eta_{\mathrm{g}} / \eta_{0}\right)$ value is considered to have a range from 14 to 18 [32]. As a result, the $m_{\min }$ value slightly fluctuates. In order to obtain the most accurate predicted Kauzmann temperature by using Equation (9), we regard the $m_{\min }$ value as a fitting parameter, which has no restrictions, and can be an arbitrary value. Therefore, we obtain the best fit and the most accurate predicted Kauzmann temperature $T_{\mathrm{K}}{ }^{\text {cal1 }}{ }^{*}$ by using Equation (9), when $m_{\min }$ equals 9.96. Although there is a difference between this value $\left(m_{\min }=9.96\right)$ and the $m_{\min }$ value obtained by $\eta_{\mathrm{g}}$ and $\eta_{0}$ of the amorphous materials, and this value may not have a physical meaning, the most accurate $T_{\mathrm{K}}{ }^{\text {cal1* }}$ by using Equation (9) at $m_{\min }=9.96$ can be obtained. Our purpose is to make the Kauzmann temperature accurately predictable, so it is feasible that the most accurate predicted Kauzmann temperature $T_{\mathrm{K}}{ }^{\text {cal1* }}$ values are obtained by using Equation (9) at $m_{\min }=9.96$. Figure $2 \mathrm{~b}$ shows the predicted Kauzmann temperature $T_{\mathrm{K}}{ }^{\text {cal1 }}{ }^{*}$, according to Equation (9) at $m_{\min }=9.96$. From Figure 2, it can be seen that the $R^{2}$ value greatly increases from 0.685 to 0.970 when the predicted values obtained by using Equation (9) at $m_{\min }=17$ are replaced by those obtained by using Equation (9) at $m_{\min }=9.96$. It indicates that the accuracy of the predicted values obtained by using Equation (9) at $m_{\min }=9.96$ are greatly improved. The predicted values obtained by using Equation (9) at $m_{\min }=17$ and 9.96 have also been listed in Table 1 for convenience in comparing the predicted $\left(T_{\mathrm{K}}{ }^{\text {cal1 }}\right.$ and $\left.T_{\mathrm{K}}{ }^{\text {cal1 }}{ }^{*}\right)$ values with the reported $T_{\mathrm{K}}$ values.

Figure 3a illustrates the predicted Kauzmann temperature $T_{\mathrm{K}}{ }^{\text {cal2 }}$ by Equation (11) at $m_{\min }=17$. Compared to Figure $2 \mathrm{a}$, the predicted Kauzmann temperature $T_{\mathrm{K}}{ }^{\mathrm{cal} 2}$ values $\left(R^{2}=0.861\right)$ obtained by Equation (11) at $m_{\min }=17$ are more accurate than those obtained by Equation (9) at $m_{\min }=17$. In order to obtain the most accurate predicted Kauzmann temperature by using Equation (11), we also regard the $m_{\min }$ value as the fitting parameter. Therefore, we obtain the best fit and the most accurate predicted Kauzmann temperature $T_{\mathrm{K}}{ }^{\text {cal2* }}$ by using Equation (11), when $m_{\min }$ equals 11.50 . Figure $3 \mathrm{~b}$ shows the predicted Kauzmann temperature $T_{\mathrm{K}}{ }^{\text {cal2 }}{ }^{*}$, according to Equation (11) at $m_{\min }=11.50$. From Figure 3 , it can be seen that the $R^{2}$ value increases from 0.861 to 0.969 when the predicted values obtained by using Equation (11) at $m_{\min }=17$ are replaced by those obtained by using Equation (11) at $m_{\min }=11.50$. The predicted values obtained by using Equation (11) at $m_{\min }=17$, and 11.50 are also listed in Table 1 .
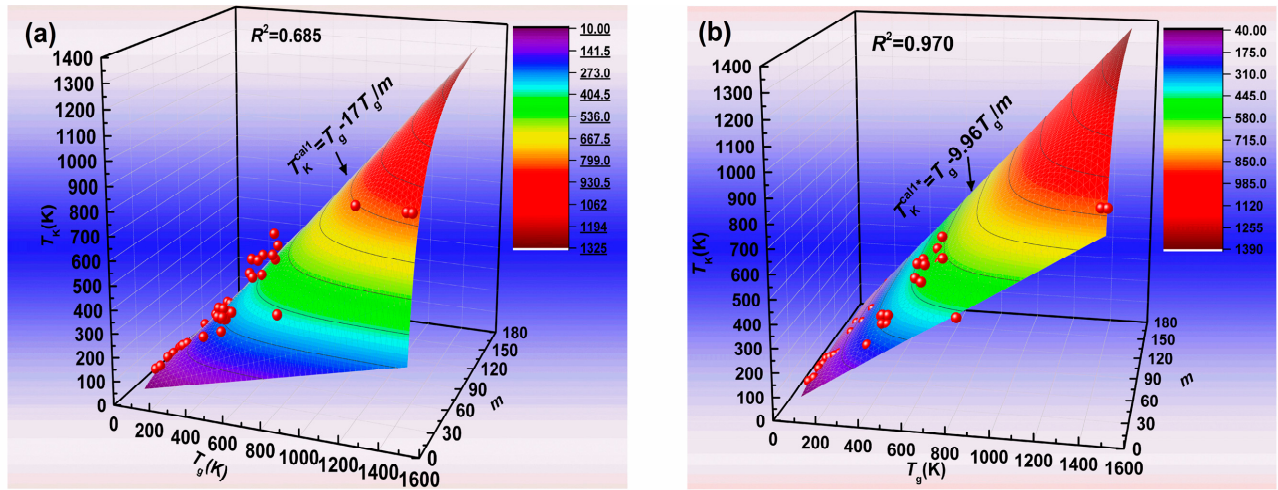

Figure 2. The predicted Kauzmann temperature obtained by Equation (9). (a) $m_{\min }=17$; (b) $m_{\min }=9.96$. 

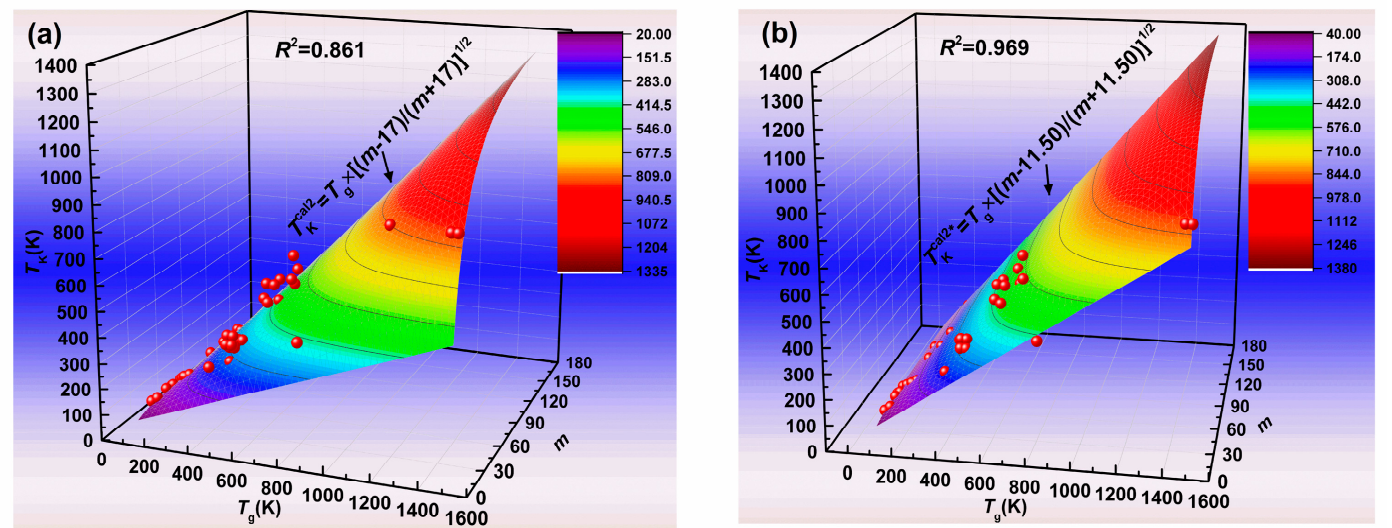

Figure 3. The predicted Kauzmann temperature obtained by Equation (11). (a) $m_{\min }=17 ;$ (b) $m_{\min }=11.50$.

Table 1. The values of $T_{\mathrm{g}}, T_{\mathrm{K}}$, and $m$ for various glass-forming liquids. The data (numbers 19-38) were taken from Ref. [17,33].

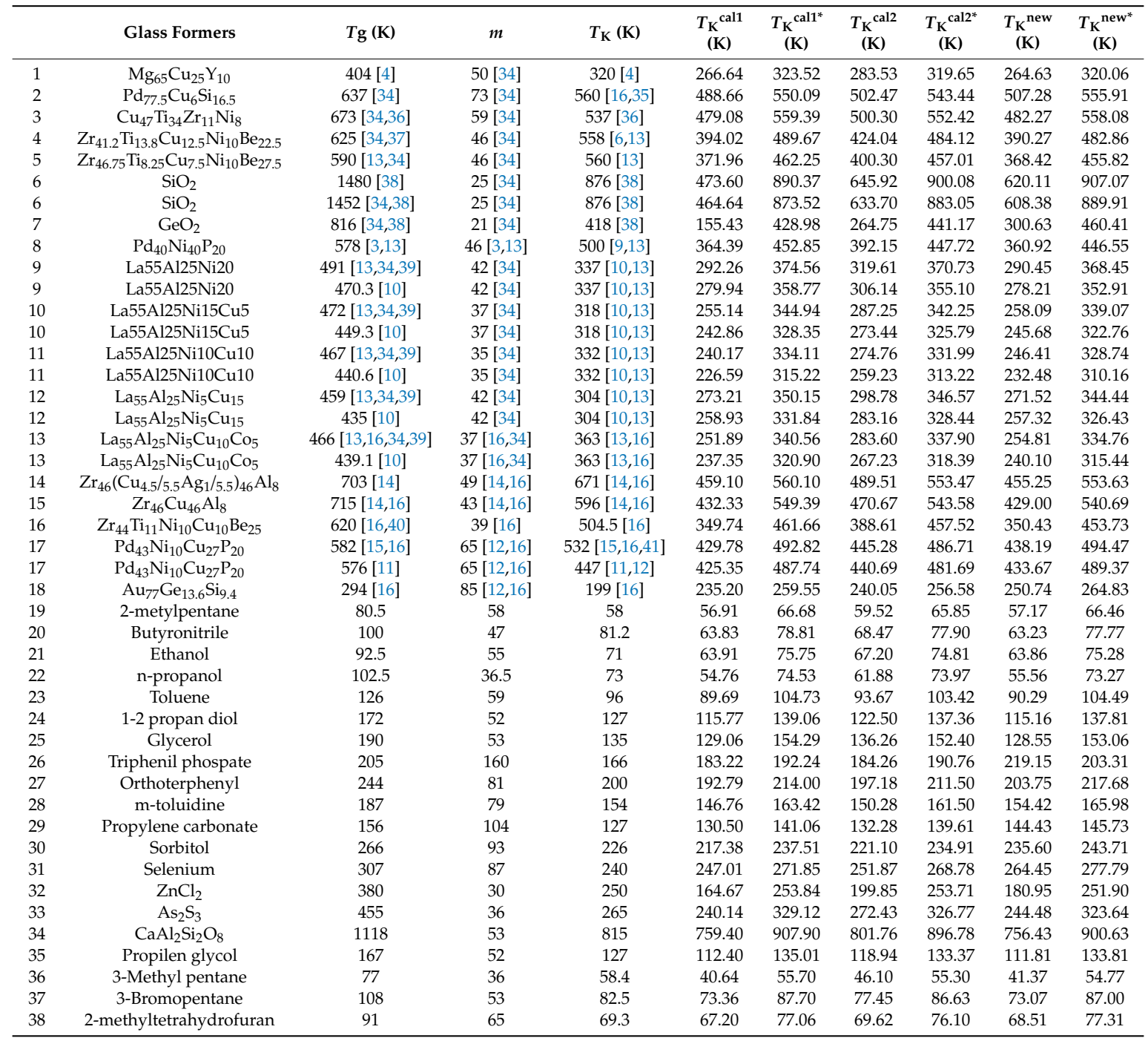

A new formula (Equation (17)) has been deduced in the above introduction, whose expression is also a function of $T_{\mathrm{g}}$ and $m$. In the literature, $\Lambda_{\mathrm{b}}$ equals 43 [27] and $\Lambda_{\mathrm{c}}$ (the ratio $T_{\mathrm{m}} / T_{\mathrm{g}}$ ) is equal to about 3/2 [27-30]. We plug these values into Equation (17), and the curve of the predicted $T_{\mathrm{K}}$ new is shown in Figure $4 \mathrm{a}$. The $R^{2}$ value of this correlation equals 0.801 . In order to obtain the most accurate 
predicted Kauzmann temperature by using Equation (17), we also regard $\Lambda_{\mathrm{b}}$ and $\Lambda_{\mathrm{c}}$ values as the fitting parameters. The best fit of the experimental data yields $\Lambda_{\mathrm{b}}=18.47$ and $\Lambda_{\mathrm{c}}=1.12$. Plugging the fitted values into Equation (17):

$$
T_{\mathrm{K}}^{\text {new* }}=1.12 T_{g}-23.17 \frac{T_{g}}{m+20.69}
$$

Figure $4 \mathrm{~b}$ shows the predicted Kauzmann temperature $T_{\mathrm{K}}{ }^{\text {new }}{ }^{*}$, according to Equation (18). From Figure 4, it can be seen that the $R^{2}$ value increases from 0.801 to 0.966 when the predicted values obtained by using Equation (17) at $\Lambda_{\mathrm{b}}=43$ and $\Lambda_{\mathrm{c}}=3 / 2$ are replaced by those obtained by using Equation (17) with the best fitting parameters (i.e., Equation (18)). The predicted values obtained by using Equation (17) at $\Lambda_{\mathrm{b}}=43$ and $\Lambda_{\mathrm{c}}=3 / 2$ and using Equation (18) are also listed in Table 1.
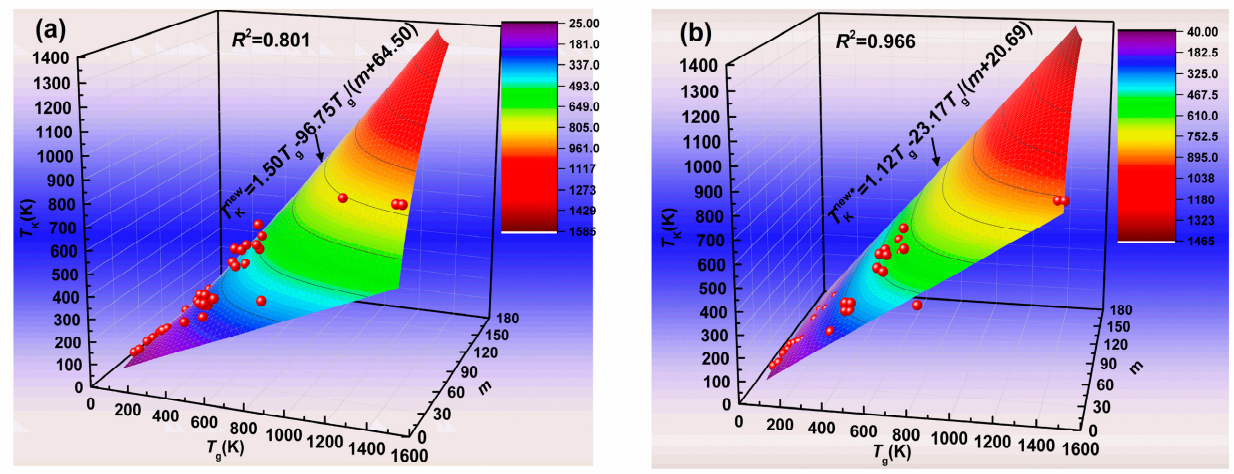

Figure 4. The predicted Kauzmann temperature obtained by Equation (17). (a) $\Lambda_{\mathrm{b}}=43$ and $\Lambda_{\mathrm{c}}=1.5$; (b) $\Lambda_{\mathrm{b}}=18.47$ and $\Lambda_{\mathrm{c}}=1.12$.

\section{Conclusions}

The Kauzmann temperature $T_{\mathrm{K}}$ in 38 kinds of amorphous materials have been predicted. Meanwhile, we regard the $m_{\min }$ value as the fitting parameter to improve the accuracy of predicting $T_{\mathrm{K}}$ values. The coefficient of determination $R^{2}$ values increase from 0.685 and 0.861 to 0.970 and 0.969 , respectively, when the coefficients of two reported relations are replaced by the best fitting parameters. In addition, a new formula of predicting $T_{\mathrm{K}}$ values with $R^{2}=0.966$ is deduced. Therefore, three equations with the best fitting parameters have relatively high $R^{2}$ values, which indicates that they can be applied to obtain the accurate predicted $T_{\mathrm{K}}$ values.

Author Contributions: Writing—original draft, Q.G.; Writing—review \& editing, Z.J.; All authors have read and agreed to the published version of the manuscript.

Funding: This research was funded by the Natural Science Foundation of China (grant numbers: 51971166 and 51671151); the State Key Laboratory of Solidification Processing in NWPU (grant number: SKLSP201812) and Foundation of Shaanxi Provincial Department of Education (grant number: 18JS050).

Conflicts of Interest: The authors declared that they have no known competing financial interests or personal relationships that could have appeared to influence the work reported in this paper.

\section{References}

1. Fiore, G.; Ichim, I.; Battezzati, L. Thermal analysis, fragility and viscosity of Au-based metallic glasses. J. Non-Cryst. Solids 2010, 356, 2218-2222. [CrossRef]

2. Glade, S.C.; Johnson, W.L. Viscous flow of the $\mathrm{Cu}_{47} \mathrm{Ti}_{34} \mathrm{Zr}_{11} \mathrm{Ni}_{8}$ glass forming alloy. J. Appl. Phys. 2000, 87, 7249-7251. [CrossRef]

3. Kawamura, Y.; Inoue, A. Newtonian viscosity of supercooled liquid in a $\mathrm{Pd}_{40} \mathrm{Ni}_{40} \mathrm{P}_{20}$ metallic glass. Appl. Phys. Lett. 2000, 77, 1114-1116. [CrossRef] 
4. Busch, R.; Liu, W.; Johnson, W.L. Thermodynamics and kinetics of the $\mathrm{Mg}_{65} \mathrm{Cu}_{25} \mathrm{Y}_{10}$ bulk metallic glass forming liquid. J. Appl. Phys. 1998, 83, 4134-4141. [CrossRef]

5. Debenedetti, P.G.; Stillinger, F.H. Supercooled liquids and the glass transition. Nature 2001, 410, $259-267$. [CrossRef]

6. Tanaka, H. Relation between thermodynamics and kinetics of glass-forming liquids. Phys. Rev. Lett. 2003, 90, 055701. [CrossRef] [PubMed]

7. Kauzmann, W. The Nature of the Glassy State and the Behavior of Liquids at Low Temperatures. Chem. Rev. 1948, 43, 219-256. [CrossRef]

8. Okamoto, P.R.; Lam, N.Q.; Rehn, L.E. Physics of Crystal-to-Glass Transformations. Solid State Phys. 1998, 52, 1-135. [CrossRef]

9. Wilde, G.; Görler, G.P.; Willnecker, R.; Fecht, H.J. Calorimetric, thermomechanical, and rheological characterizations of bulk glass-forming $\mathrm{Pd}_{40} \mathrm{Ni}_{40} \mathrm{P}_{20}$. J. Appl. Phys. 2000, 87, 1141-1152. [CrossRef]

10. Lu, Z.P.; Li, Y.; Liu, C.T. Glass-forming tendency of bulk La-Al-Ni-Cu-(Co) metallic glass-forming liquids. J. Appl. Phys. 2003, 93, 286-290. [CrossRef]

11. Fan, G.J.; Löffler, J.F.; Wunderlich, R.K.; Fecht, H.J. Thermodynamics, enthalpy relaxation and fragility of the bulk metallic glass-forming liquid $\mathrm{Pd}_{43} \mathrm{Ni}_{10} \mathrm{Cu}_{27} \mathrm{P}_{20}$. Acta Mater. 2004, 52, 667-674. [CrossRef]

12. Fan, G.J.; Choo, H.; Liaw, P.K. Fragility of metallic glass-forming liquids: A simple thermodynamic connection. J. Non-Cryst. Solids 2005, 351, 3879-3883. [CrossRef]

13. Tanaka, H. Relationship among glass-forming ability, fragility, and short-range bond ordering of liquids. J. Non-Cryst. Solids 2005, 351, 678-690. [CrossRef]

14. Jiang, Q.K.; Wang, X.D.; Nie, X.P.; Zhang, G.Q.; Ma, H.; Fecht, H.J.; Bendnarcik, J.; Franz, H.; Liu, Y.G.; Cao, Q.P.; et al. Zr-(Cu,Ag)-Al bulk metallic glasses. Acta Mater. 2008, 56, 1785-1796. [CrossRef]

15. Gallino, I.; Schroers, J.; Busch, R. Kinetic and thermodynamic studies of the fragility of bulk metallic glass forming liquids. J. Appl. Phys. 2010, 108, 063501. [CrossRef]

16. Fontana, G.D.; Battezzati, L. Thermodynamic and dynamic fragility in metallic glass-formers. Acta Mater. 2013, 61, 2260-2267. [CrossRef]

17. Ruocco, G.; Sciortino, F.; Zamponi, F.; De Michele, C.; Scopigno, T. Landscapes and fragilities. J. Chem. Phys. 2004, 120, 10666-10680. [CrossRef]

18. Battezzati, L.; Castellero, A.; Rizzi, P. On the glass transition in metallic melts. J. Non-Cryst. Solids 2007, 353, 3318-3326. [CrossRef]

19. Li, P.; Wang, G.; Ding, D.; Shen, J. Glass forming ability and thermodynamics of new Ti-Cu-Ni-Zr bulk metallic glasses. J. Non-Cryst. Solids 2012, 358, 3200-3204. [CrossRef]

20. Böhmer, R.; Ngai, K.L.; Angell, C.A.; Plazek, D.J. Nonexponential relaxations in strong and fragile glass formers. J. Chem. Phys. 1993, 99, 4201-4209. [CrossRef]

21. Venkataraman, S.; Biswas, K.; Wei, B.C.; Sordelet, D.J.; Eckert, J. On the fragility of $\mathrm{Cu}_{47} \mathrm{Ti}_{33} \mathrm{Zr}_{11} \mathrm{Ni}_{8} \mathrm{Si}_{1}$ metallic glass. J. Phys. D Appl. Phys. 2006, 39, 2600-2608. [CrossRef]

22. Meng, Q.G.; Zhang, S.G.; Li, J.G.; Bian, X.F. Strong liquid behavior of $\operatorname{Pr}_{55} \mathrm{Ni}_{25} \mathrm{Al}_{20}$ bulk metallic glass. J. Alloys Compd. 2007, 431, 191-196. [CrossRef]

23. Zhao, Z.F.; Zhang, Z.; Wen, P.; Pan, M.X.; Zhao, D.Q.; Wang, W.H.; Wang, W.L. A highly glass-forming alloy with low glass transition temperature. Appl. Phys. Lett. 2003, 82, 4699-4701. [CrossRef]

24. Waniuk, T.A.; Busch, R.; Masuhr, A.; Johnson, W.L. Equilibrium viscosity of the $\mathrm{Zr}_{41.2} \mathrm{Ti}_{13.8} \mathrm{Cu}_{12.5} \mathrm{Ni}_{10} \mathrm{Be}_{22.5}$ bulk metallic glass-forming liquid and viscous flow during relaxation, phase separation, and primary crystallization. Acta Mater. 1998, 46, 5229-5236. [CrossRef]

25. Fontana, G.D.; Castellero, A.; Battezzati, L. Thermodynamics and fragility of Fe-based glass forming melts. J. Non-Cryst. Solids 2016, 433, 103-108. [CrossRef]

26. Busch, R.; Bakke, E.; Johnson, W.L. Viscosity of the supercooled liquid and relaxation at the glass transition of the $\mathrm{Zr}_{46.75} \mathrm{Ti}_{8.25} \mathrm{Cu}_{7.5} \mathrm{Ni}_{10} \mathrm{Be}_{27.5}$ bulk metallic glass forming alloy. Acta Mater. 1998, 46, 4725-4732. [CrossRef]

27. Wang, L.M.; Angell, C.A.; Richert, R. Fragility and thermodynamics in nonpolymeric glass-forming liquids. J. Chem. Phys. 2006, 125, 074505. [CrossRef]

28. Hunt, A. A simple connection between the melting temperature and the glass temperature in a kinetic theory of the glass transition. J. Phys. Condens. Matter 1992, 4, L429-L431. [CrossRef]

29. Hunt, A. An explanation for the correlation between the glass transition temperature and the extrapolated divergence of the viscosity in Vogel-Fulcher phenomenology. Solid State Commun. 1993, 88, 377-379. [CrossRef] 
30. Lubchenko, V.; Wolynes, P.G. Barrier softening near the onset of nonactivated transport in supercooled liquids: Implications for establishing detailed connection between thermodynamic and kinetic anomalies in supercooled liquids. J.Chem. Phys. 2003, 119, 9088-9105. [CrossRef]

31. Kato, H.; Wada, T.; Hasegawa, M.; Saida, J.; Inoue, A.; Chen, H.S. Fragility and thermal stability of Ptand Pd-based bulk glass forming liquids and their correlation with deformability. Scripta Mater. 2006, 54, 2023-2027. [CrossRef]

32. Gao, Q.; Jian, Z.Y. Measured and ideal glass transition temperatures of glass-forming liquids. J. Mol. Liq. 2019, 296. [CrossRef]

33. Huang, D.; McKenna, G.B. New insights into the fragility dilemma in liquids. J. Chem. Phys. 2001, 114, 5621-5630. [CrossRef]

34. Senkov, O.N. Correlation between fragility and glass-forming ability of metallic alloys. Phys. Rev. B 2007, 76. [CrossRef]

35. Fiore, G.; Battezzati, L. Thermodynamic properties of the $\mathrm{Pd}_{77.5} \mathrm{Cu}_{6} \mathrm{Si}_{16.5}$ undercooled liquid. J. Alloys Compd. 2009, 483, 54-56. [CrossRef]

36. Glade, S.C.; Busch, R.; Lee, D.S.; Johnson, W.L.; Wunderlich, R.K.; Fecht, H.J. Thermodynamics of $\mathrm{Cu}_{47} \mathrm{Ti}_{34} \mathrm{Zr}_{11} \mathrm{Ni}_{8}$, $\mathrm{Zr}_{52.5} \mathrm{Cu}_{17.9} \mathrm{Ni}_{14.6} \mathrm{Al}_{10} \mathrm{Ti}_{5}$ and $\mathrm{Zr}_{57} \mathrm{Cu}_{15} .4 \mathrm{Ni}_{12.6} \mathrm{Al}_{10} \mathrm{Nb}_{5}$ bulk metallic glass forming alloys. J. Appl. Phys. 2000, 87, 7242-7248. [CrossRef]

37. Kim, Y.J.; Busch, R.; Johnson, W.L.; Rulison, A.J.; Rhim, W.K. Metallic glass formation in highly undercooled $\mathrm{Zr}_{41.2} \mathrm{Ti}_{13.8} \mathrm{Cu}_{12.5} \mathrm{Ni}_{10.0} \mathrm{Be}_{22.5}$ during containerless electrostatic levitation processing. Appl. Phys. Lett. 1994, 65, 2136-2138. [CrossRef]

38. Sipp, A.; Bottinga, Y.; Richet, P. New high viscosity data for 3D network liquids and new correlations between old parameters. J. Non-Cryst. Solids 2001, 288, 166-174. [CrossRef]

39. Lu, Z.P.; Goh, T.T.; Li, Y.; Ng, S.C. Glass formation in La-based La-Al-Ni-Cu-(Co) alloys by Bridgman solidification and their glass forming ability. Acta Mater. 1999, 47, 2215-2224. [CrossRef]

40. Evenson, Z.; Busch, R. Equilibrium viscosity, enthalpy recovery and free volume relaxation in $\mathrm{Zr}_{44} \mathrm{Ti}_{11} \mathrm{Ni}_{10} \mathrm{Cu}_{10} \mathrm{Be}_{25}$ bulk metallic glass. Acta Mater. 2011, 59, 4404-4415. [CrossRef]

41. Kuno, M.; Shadowspeaker, L.A.; Schroers, J.; Busch, R. Thermodynamics of The $\mathrm{Pd}_{43} \mathrm{Ni}_{10} \mathrm{Cu}_{27} \mathrm{P}_{20} \mathrm{Bulk}$ Metallic Glass Forming Alloy. MRS Proc. 2004, 806. [CrossRef] 